\title{
Choreographing the glitch
}

\author{
Beverley Hood \\ Edinburgh College of Art \\ University of Edinburgh \\ Lauriston Place \\ Edinburgh, EH3 9DF \\ b.hood@ed.ac.uk
}

\begin{abstract}
glitching is a digital installation and performance art project that attempts to re-describe movement derived from characters in contemporary sports and action computer games.

Gaming characters of the 21st century have an extraordinary embodiment, fluidity of movement and naturalness, becoming more and more realistic and convincing, thanks to constant improvements in technology. However, there are always exceptions; disruptions, imperfections and glitches, whether through unexpected programming errors, forced "cheats" or the users' inability to control the characters in seamless game-play. There is still the potential for awkwardness, otherness and instability between spells of perfection.
\end{abstract}

glitching re-focuses the artificial nature of these disruptions by employing highly trained real bodies i.e. professional dancers, to re-stage them. The project attempts to interrogate how real bodies cope with, and interpret into sequences of choreography, the limits of such foreign and unnatural movement and subsequently, how this physically re-enacted choreography can be embedded and re-imaged within a responsive digital environment.

Appropriating the premise of the latest home entertainment dance and training games, glitching employs the motion-sensor controller Microsoft Xbox Kinect, large-screen display and a pseudo game interface, to create a full-body, skeletally controlled, interactive experience. The audience is invited to step into the digital shoes of a 'lead dancer' character, and attempt to follow the awkward and intricate, glitch choreography performed by the dancing troupe on screen.

In conjunction with the installation there are a series of glitching live performances featuring dancers Tony Mills, Hannah Seignior, Felicity Beveridge, a performance soundtrack devised by Martin Parker and the interactive installation as backdrop.

Glitch, glitching, Kinect, performance, art, physical interaction, choreography, installation

\section{INTRODUCTION}

To reflect on the intersections between humans and machines, and wonder what the unceasing developments in science and technology might mean for being human. (Taylor, 2012)

This eloquently simple yet astute statement from Alex Taylor, Sociologist at the Microsoft Research (MSR) Cambridge Lab, about his research goals, resonates with for my own aspiration as an artist, having spent the past sixteen years creating digital media projects that interrogate the impact of technology on the body, relationships and human experience. This has resulted in a diverse body of work, with a range of forms and media including: websites, real-time 3D, animation, interactive installation, digital prints, mobile short films and game art.
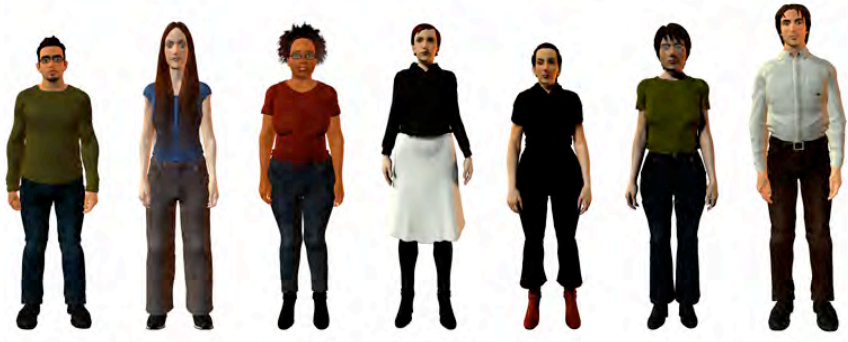

Figure 1: Doppelganger 2012. Digital prints. Copyright: Beverley Hood.

Throughout this time, I have undertaken numerous collaborations with a wide array of practitioners from within the fields of art, science, and technology, including dancers, writers, programmers and dermatologists, in an effort to explore human interactions and interfaces with technology. 
Although, I would argue that my scrutiny of our complex relationship to technology is current, I also recognise that this creative line of enquiry is not a novel undertaking. Extraordinary historical works from a range of creative practices, including Mary Shelley's Frankenstein (first published in 1818), are significant demonstrations of much earlier investigations into the implications, influence and pressure exerted upon human existence by technology, development and industry.

Mary Shelley's Frankenstein makes the first posthuman life form of a modern age... Shelley writes far in advance of the digital computers which later begin to effect such developments, but she clearly feels the stirrings of artificial life even as industrialization begins and does much to programme the dreams and nightmares of the next two centuries... (Plant, 2000, p. 265-275)

My digital art projects operate as both as both cultural artefacts and practice based research, existing within and beyond the academic framework, into the gallery, museum and wider art world. Through my creative practice I attempt to generate projects that are both recognised research outputs and cultural manifestations. This requisite for academic creative practitioners creates a continual struggle, wrestling with the expectations and conventions of divergent worlds. The projects that I create are distinct from early twenty-first century positivist influenced research, dominated by "a paradigm based on an invisible observer, conducting unbiased, objective, repeatable, verifiable experiments." (Kozel, 2011, p. 10). Central to my approach to creative practice is an attempt to question, interrogate and often problematize through the utilisation of artistic process, as a critical tool of engagement and method of enquiry. I attempt to interweave theoretical research within discerning artistic methodology, closely linking process of production, form and media to the concept being explored and interrogated. The aim is that artistic form and process develop in parallel and resonate with concept. My practice, I would argue, can be seen as an example of Kozel's interpretation of a phenomenological approach; exploring the possibilities highly subjective, intuitive, and experiential ways to negotiate technology that can resonate on many levels: cognitive, emotional, physical. It is a practice that revels in "the seemingly illogical, nonsensical, ambiguous, or even the preposterous or the sublime." (Kozel, 2011, p. 19).

\section{COMMISSIONING GLITCHES}

My most recent artwork, glitching, is a digital installation and performance project that attempts to re-describe the movement derived from characters in contemporary sports and action computer games. Commissioned by the Scotland \& Medicine partnership for the exhibition Human Race: inside the history of sports medicine (with additional funding from Creative Scotland and Edinburgh College of Art), the project tours museums and galleries in Scotland throughout 2012, as part of The Scottish Project, an official part of the London 2012 Cultural Olympiad. The exhibition presents historical artefacts alongside newly commissioned artworks to examine the relationship between sport, exercise and the body, organised around themes such as pushing limits and breaking boundaries (Chilcott and MacCallum 2012).

My approach to this commission was to scrutinise contemporary manifestations of sports, exercise, training within gaming, the technology that has emerged around this, and the wider impact that contemporary gaming has upon our perceptions of the body, physicality and presence. Central to my enquiry was a focus on malfunction, interference instability, i.e. the glitch.

The gaming world is voracious in harnessing, driving and implementing, the constant and rapid improvements in technology. As it grows ever more sophisticated and ubiquitous, the movements of characters become more and more realistic and convincing. Gaming characters of the 21st century have an extraordinary embodiment, fluidity of movement and naturalness. This virtual physicality is often derived from the real; games such FIFA, use motion capture and body scanning of professional sports players to create convincing, highly distinct individualistic motion sequences to be used within real-time gameplay (Mills, 2011).

However, there are always imperfections, interference and glitches, whether through unexpected programming errors, the users' inability to control the characters in seamless game-play (resulting in bumping into walls, misfiring, etc.) or the fully intentional cheat. There is still the potential for awkwardness, otherness and instability, between spells of perfection and it is this unintentional, uncontrollable disruption that I am interested in.

Glitches are a rich area of artistic enquiry, with entire publications and virtual museums devoted to artists and designers inspired by the glitch, for instance the IdN: Glitch Issue, 2011 and Mark America's project The Museum of Glitch Aesthetics. The American artist, Clement Valla, used the glitch as source and reference for a series of digital images, Postcards from Google Earth (see Figure 2), which exploit the disruptive, imperfect, and problematic rendering of certain physical terrains by Google Earth. Valla sites his 
interest in glitches deriving from the fact that "Glitches generate forms that no individual has thought of or set out to create. Rather, they result from the interaction of the material processes (glitches due to hardware), the code (glitches due to software), and the user or programmer." (Valla, 2011)

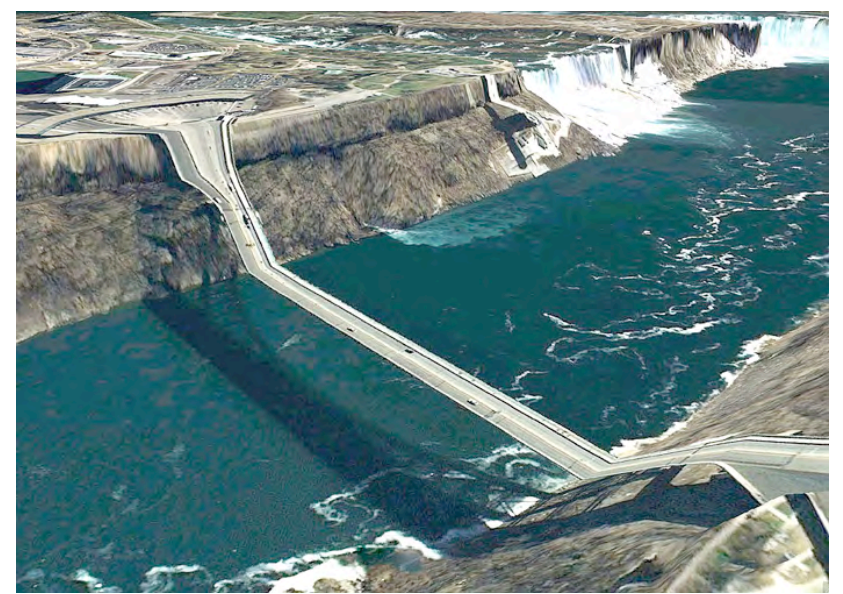

Figure 2: Postcards from Google Earth 2011. Digital image. Copyright: Clement Valla.

The artist collective JODI, are well known for their artistic tactics of modification, disruption and interference. In 2006, they created Max Payne Cheats only, a work derived from the glitches and cheats within the video game Max Payne 2: The Fall of Max Payne, developed by Remedy Entertainment. In this work JODI captured glitch/cheat alternatives to the prescribed gameplay choices, pathways and pursuits of the Max Payne characters, to create a series of short videos. The resulting artwork exposes vacuous characters, endlessly repeating absurd cycles of perpetual motion (jumping, loading weapons, subsuming camera), boxed into digital dead ends; in toilet cubicles, stairways and back lanes, digressing from the main game action. The characters are further isolated from their origin and purpose by the artists reorganisation of these looped video captured sequences, within a numerically organised index of webpages, an ambiguous construct that imparts no information pertaining to its derivation or meaning.

Jodi have intervened in the programme structure in such a way that absurd perspectives and effects alter the game's otherwise realistic graphics: we see the massive hero repeating idiotic movements; he dips his angular head into a virtual matrix; his body appears semi-transparent. (transmediale festival, 2006)

\section{FROM GLITCH TO GLITCHIING}

The glitching project, focuses on the absurd, artificial, disruptive and unstable nature of bodily movement that transpires during gaming character glitches. My research into the occurrence of these glitches was assisted hugely, by the reams of game-play footage posted on YouTube, by gamers. The phenomena of posting video captures of individual game-play, means that a vast amount of data exists online demonstrating glitches and cheats from almost every game title on the market (see Figure 3). A simple search for "glitches" on youtube.com brings back about 344,000 results. For the glitching project, this immense database was filtered down into a library of approximately 75 glitch instances, by selecting best quality captures of duplicates (for example "Skate 3 Super Jump glitch" brings back 885 results).

The important question for me was how this collection of glitches (artificial, alternate, other movements), might be deconstructed, reembodied, and re-staged by applying to the human body. Attempting to interrogate whether by taking the digital and transplanting it, re-interpreting it, embodying it within the physical body - literally reenacting it - would it disintegrate, transform, and become something new?

To undertake this enquiry, I employed highly trained, real bodies i.e. professional dancers. The primary dancer I worked with was breakdance world champion Tony Mills, a performer of "compelling expressiveness and versatility" (Brennan, 2010) with an extraordinary ability to interpret, create and enact awkward, extreme and atypical movements. Tony's creative practice bridges the international "breaker" world, with his BBoy crew Random Aspekts, alongside performances with international contemporary dance companies, such as Derevo, Curious Seed and his own dance performance company Room2Manoeuver.

Tony and I attempted to foster a collaborative research and production environment, which would enable us to discuss, question and create through a rigorous process of critical deconstruction and construction, across disciplinary constraints. The aim of this collaborative relationship was to foster complexity, depth and meaning in the integration of concept, process and form.

We attempted to collaboratively interrogate how real bodies cope with (and interpret into sequences of choreography) the potential and limits of the foreign, unnatural movement of computer glitches. A creative pioneer analysing the limitations of the human body, physical conventions, and potentially "redefining what the body can do" (Monahan, 2010) is choreographer, Wayne McGregor and his radical dance company Random Dance. McGregor's 2010 production Far, attempted to establish a "radical cognitive research process" (Random Dance, 2012) drawing upon the input of neurologists to "un-pick" conventions within dancer's individual 
vocabularies of movement, disrupting and challenging patterns of behaviour. The resulting work revels in absurd, unconventional, highly individualistic and idiosyncratically performed choreography.

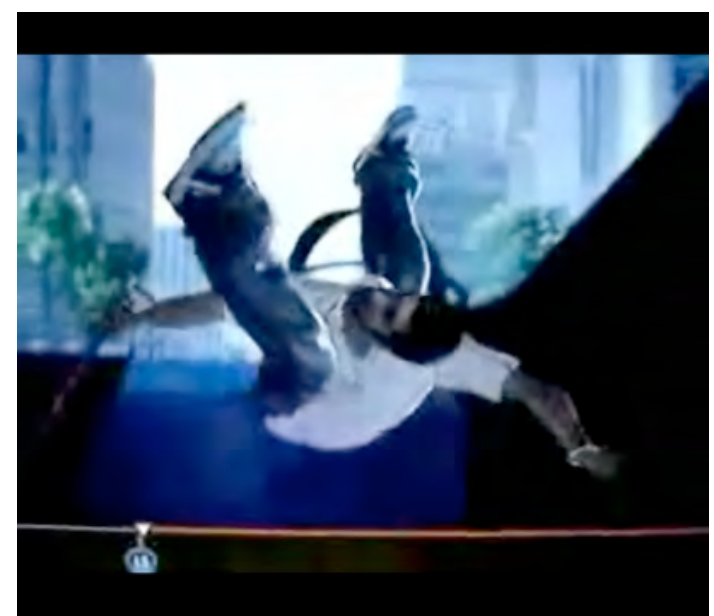

Figure 3: Skate for Xbox 360 2007. Copyright: Electronic Arts.

glitching was choreographed by drawing from our YouTube video library, and establishing collectively defined glitch categories, including "jitters", "rogue limbs" and "impossible moves" i.e. movements seemingly only possible within a digitally constructed body, beyond the limits of human potentiality. Tony Mills was the physical conduit, attempting to decipher, re-structure, and enact the individual glitches, whilst continually responding to my creative critique, questioning and contribution.

Through a considered but open, focused but nonprecious process of production, we collaboratively created choreographed sequences. Individual glitch re-enactments were antagonistically sequenced, to create un-harmonious, anti-flowing, provocative pairings and relationships. Once constructed and reconciled, these established sequences were deconstructed and re-arranged; transformed by an alternatives such as orientation (i.e. standing sequence translated to the floor), randomised order and adjusted duration. This choreographic process included the establishment of an overall physical texture to the re-enacted glitches, including tight muscular control based on popping techniques, non-symmetry, and offbeat tempo (i.e. not working to a typical 4, 8, 16 bar count). Furthermore, we considered the behavioural qualities of computer game characters, as potential examples of Kozel's pre-reflective state; permanently active performers, even in 'idle' mode, locked into the immediate moment. Unaware of ensuing data requests, these "non-knowing" characters are actively fixed in a series of looped data feeds or performance states, instilling them with an air of being simultaneously present and distant (2011).
This fluid, iterative production process was established through a series of short collaborative development workshops over a period of four months. Ultimately, this activity resolved into the creation of a four minute choreographic sequence, set to a soundtrack 'Video Computer System' by Brazilian electronic music duo Golden Shower.

\section{EMBEDDING THE INTERFERENCE - CHOREOGRAPHING THE INTERFACE}

The glitching project attempts to consider how these character glitches, physically re-interpreted in to sequences of choreography, can subsequently be embedded and re-presented within a responsive installation environment, for an audience to interact with.

Initially, this entailed digitising both the physically enacted glitch choreography, and performer, Tony Mills. Central to this process was the motion controlled sensor, Microsoft Xbox Kinect. Marketed as a gaming controller but infamously hacked only a few days after its release in 2010 (BBC, 2010), the Kinect is an extraordinary example of gesture driven hardware, accessible and affordable, with radical potential for creating physicality based interaction. Microsoft emphasise its potential, when used in tandem with their Kinect Software Development Kit (SDK), in the hands of developers, to create natural user interfaces (NUI) (Microsoft Research, 2012). I wholeheartedly recognise the relevance of developers, programmers and technologists in this area of enquiry, especially since the Kinect is not an easy tool to tackle without significant technical competence. However, I would argue that creative practitioners are equally important within this development, to interrogate, question and reexamine the implications, potential and resistance of gesture driven, physicality based interaction.

The Kinect SDK uses a twenty point (or joint) skeletal tracking system, allowing the whole body to be digitally mapped. However, the data generated from this tracking is always an approximation, based on algorithmic assumptions, open to disturbance and noise (such as the effect of bright sunlight), it is variable and contingent.

In the glitching project, the Kinect was initially utilised as a motion capture device to digitise the physically enacted glitch choreography, performed by Tony Mills. Pre-existing hacks, plugins and commercially available Motion Capture software, developed specifically for the Kinect were trialled, evaluated and experimented with. This enormously rich, but immature technology has been radically exploited (Microsoft, 2012), with a multitude of uses, users and channels of distribution. Unfortunately, as a result, the reality of working with the Kinect presents an unstable development 
environment, rife with technical difficulties, inconsistencies, and frustration.

In light of the glitching project's conceptual embrace of interference, instability and malfunction, we attempted to harness the Kinect's disruptions and inconsistencies, as constructive matter to feed back into the project. For example, trialling the Kinect as a motion capture device with the freeware vocaloid animation software MikuMikuDance, (created by the Vocaloid Promotion Video Project) generated a fresh manifestation of the glitch choreography, reconfigured amidst digital noise and skeletal misinterpretation. The resulting data, collated as digital video sequences, were subsequently used as reference material to modify the texture, countenance and characteristics of the physical choreography.

Ultimately, the conclusive glitch choreography sequence was captured using the iPi Desktop Motion Capture System, and applied to a computer generated 3D model of Tony Mills. The digital Tony was constructed by appropriating and adapting preexisting character models, available within Autodesk MotionBuilder 2012's 'Content' libraries and Unity 3 Game Engine's 'Asset Store'.

Choreographing the interaction between audience, computer generated model and glitch choreography was the ensuing challenge. To bring computer generated movement i.e. glitches, into the real world and then playfully attempt to interweave this back and forth between the digital and real world environment, exploring overlaps, tensions and distortions evolved early on as an astute and pertinent tactic. Central to this approach was an inquiry into the possibilities of embedding physicality-based interaction. As a result, glitching appropriates the premise of current home entertainment dance and fitness training games (such as Just Dance, Dance Central and Your Shape:Fitness Evolved). Employing Microsoft's Xbox Kinect (in its original function as a motionsensor controller), a pseudo gaming environment and large-screen display, glitching presents a fullbody interaction, digital installation for the public to "play" (see Figure 4).

The glitching "game" was developed in C\# using the Unity 3 Game Engine and the Microsoft Kinect SDK. Employing the expertise of experienced games developer, Hemal Bodasing, pre-existing Kinect plugins were evaluated and considered. Consequently, the Carnegie Mellon University's Kinect Wrapper Package for Unity was adopted, fulfilling fundamental functionality, and providing an initial technical development base. Hemal subsequently adapted and re-shaped the Kinect Wrapper/Kinect SDK relationship to suit the requirements of glitching. The development process was iterative and agile, happening in short, often weekly, cycles.

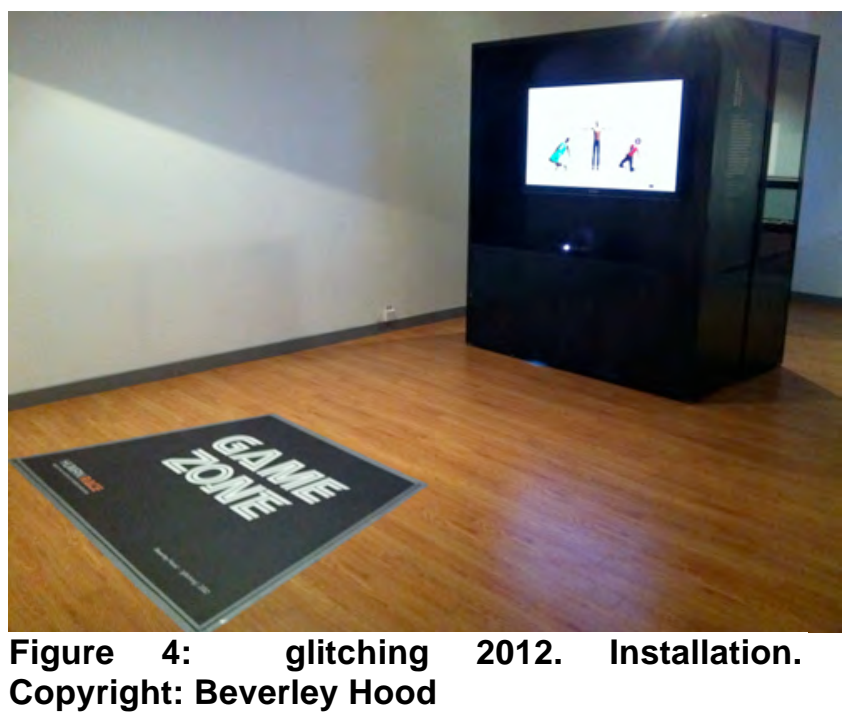

The result is a stand-alone Unity project, running on PC platform (Windows 7), installed with the Microsoft Kinect SDK drivers. Using skeletal tracking, the Kinect attempts to trace the entire viewer's body, transferring their movements onto the 'lead digital dancer'; the Tony Mills character, centrally positioned within the digital "game" interface (see Figure 5). Stepping into this full-body controlled mechanism, enables the viewer to be copresent "with that which is other to itself" (Giannachi and Kaye, 2011, p. 7), physically inhabiting the digital character. The co-present viewer is able to virtually trigger the glitch choreography, performed by the two digital backing dancers on-screen, and attempt to follow the awkward and intricate choreographic sequence in action.

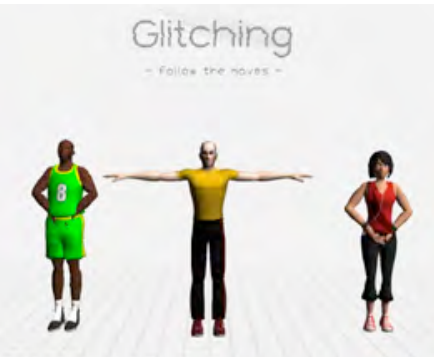

Figure 5: glitching 2012. Interactive installation interface. Copyright: Beverley Hood

On the surface, the Microsoft Xbox Kinect appears to present an uncanny example of Donna Haraway's proposition that "The difference between machine and organism is thoroughly blurred; mind, body and tool are on very intimate terms" (2000, p.50-56). However, glitching reveals that this blurring is regularly brought sharply into focus, 
since an encounter with the Kinect is in itself rife with interference, resistance and glitches. As the participating viewer attempts to follow the glitch choreography onscreen, their movements are distorted, transformed and contingent, due to skeletal limitations, (mis)interpretation and unreliability of the data from the Kinect. Akin with Giannachi and Kaye's analysis of presence, where the 'I am' interacts with that which is before or in front "the environment generated by this process, is not neutral but rather charged, fraught with tension." (Giannachi and Kaye, 2011, p.6). This dynamic physical interface creates an additional layer of glitch within the live interactive experience; improvised, unpredictable and uncontrollable. The participating viewer is both an active and disruptive contributor.

\section{PERFORMANCE DISRUPTION INTERFERING WITH THE GLITCH}

Presented in conjunction with the glitching installation, are a series of live glitching performances (see Figure 6). Utilising the digital installation as backdrop, source and reference, the performance is presented as a production in five parts, executed as a series of expanded glitch cycles, with a running time of approximately 30minutes. The performance was devised collectively through a series of development workshops with dancers Tony Mills, Hannah Seignior, Felicity Beveridge, and composer Martin Parker, over a four month period in 2012. To this, Tony and I brought the already existing glitch choreography and Kinect technology (from the digital installation), as source material to encompass and build upon. The performance concludes with an invitation for the audience to step on stage to 'play' and interact with the digital installation interface.

Throughout the development we presented "showings" (informal presentations of the performance in-progress), to a small invited audience, the feedback from which was built into subsequent project development. This iterative, collective and open development process, brought about technological adaptation, radical reconstruction of the original glitch choreography sequences, refinement of performance qualities and composition of an audio environment that included both a set soundtrack and improvised, performer controlled audio, enacted using a gaming controller on stage.

Embedded within the glitching project are multiple copies, versions, distortions and deviations: the physical movement "source" Tony Mills, the motion captured data, translated and re-interpreted by software, the re-enactment of this within the Unity game engine, and the distortion applied by the Kinect sensor in its translation of the participating

viewer's movements. In the performance, this layering of copies and versions is taken to another level, with the source, Tony Mills, coming back on stage to dance with a distilled, re-interpreted, and disruptive, representational other of himself.

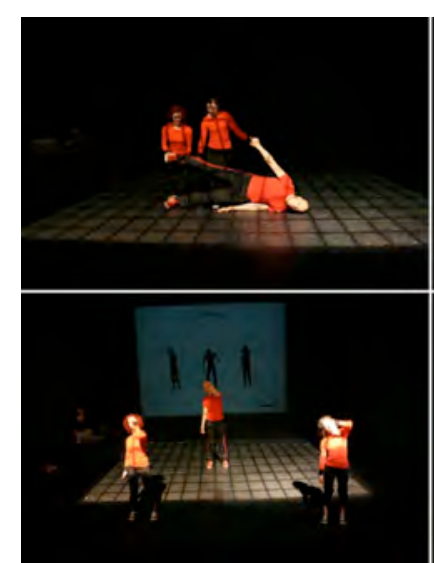
Figure 6: glitching 2012. Performance.
Copyright: Kim Beveridge.

Real world echos, in the form of Hannah Seignior and Felicity Beveridge, become yet more copies, but in this case human embodiments, bringing their own personal, physiological and phenomenal interpretations. The choreographic material, appears in an array of divergent iterations, each imprinted with the qualities and effect of its processing whether physical enactment or data interpretation. glitching resonates, with Marcel Duchamp's thoroughly inconsistent (and mostly undefined), but potent concept of infra-mince as suggested by Gavin Parkinson, i.e. that it is concerned with "manifesting a sense of 'slippage' of loss, lack or infinite multiplicity - threatening at once the unity of the self and the possibility of an absolute comprehension of the world." (Parkinson, 2008, p.78). glitching absorbs and revels in the disintegration, misinterpretation and unreliability of the exchange of data from one source to another.

\section{CONCLUSION}

glitching sits within a diverse, rich body of creative projects, exploring the limitations, disruptions and malfunctions of technology, as potentially constructive attributes. It is also an attempt to investigate the potential of motion controlled, gesture driven technology as a tool to create physicality based interaction within installation and performance.

The project constructively assimilates Rinehart's adaption (motivated by the emergence of digital art) of Benjamin's assertion that "the work of art reproduced becomes the work of art designed for reproduction" (Rinehart ,2010). This reproducibility is embedded within concept, development process and final artwork, which exists now, as multiple 
releases, adapting to its presentation environment whether installation or performance.

Michael Freid asserted that "art degenerates as it approaches the condition of theatre" (Fried, 1968, p. 116-147). If this is the case I would gladly argue that glitching is intentionally, highly degenerative.

\section{REFERENCES}

BBC. (2010) Kinect hacked days after release. BBC News - Technology, 12 Nov 2010. Available from: http://www.bbc.co.uk/news/technology11742236 (14 June 2012)

Brennan, M. (2010) Such a Bloke/Watch iT! The Arches, Glasgow. The Herald, 8 Oct 2010. Available from: http://www.heraldscotland.com/arts-ents/stagevisual-arts/such-a-bloke-watch-it-the-archesglasgow-1.1060148 (16 Aug 2012)

Microsoft. (2012) Channel 9. Microsoft Forum. Available from:

$\mathrm{http}: / /$ channel9.msdn.com/search?term=kinect (9 Aug 2012)

Chilcott, K., and MacCallum, M. (2012) Human Race: inside the history of sports medicine. Exhibition Guide. Edinburgh: Scotland \& Medicine: Collections \& Connections.

Fried, M. (1968) Art and Objecthood. In: Battcock, G. (eds). Minimal Art: A Critical Anthology. New York: E.P. Dutton \& Co. 116147.

Giannachi, G., and Kaye, N. (2011) Performing Presence: Between the live and the simulated. Manchester: Manchester University Press. 6, 7.

Haraway, D. J. (2000) A Manifesto for Cyborgs: Science, Technology, and Socialist Feminism in the 1980s. . In: Kirkup, G., Janes, L., Woodward, K. and Hovenden, F. (eds). The Gendered Cyborg. London: Routledge. 50-56.

Kozel, S. (2011) Closer : Performance, Technologies, Phenomenology. Cambridge: Leonardo/The MIT Press.
Mills, T. (2011) FIFA12: Motion Capture. FIFA Soccer Blog. Available from:

http://fifasoccerblog.com/blog/fifa12-motioncapture/ (2 Aug 2012)

Microsoft Research. (2012) Kinect for Windows SDK Beta. Available from:

http://research.microsoft.com/enus/collaboration/focus/nui/kinect-windows.aspx (7 June 2012)

Monahan, M. (2010) FAR, Wayne McGregor, Random dance, review. The Telegraph, $18 \mathrm{Nov}$ 2010. Available from:

http://www.telegraph.co.uk/culture/theatre/danc e/8143522/FAR-Wayne-McGregor-Randomdance-review.html (7 June 2012)

Parkinson, G. (2008) Essential Artists: The Duchamp Book, London: Tate Publishing. 78.

Plant, S. (2000) On the matrix: cyberfeminist simulations. In: Kirkup, G., Janes, L.,

Woodward, K. and Hovenden, F. (eds). The Gendered Cyborg. London: Routledge. 265275.

Random Dance. (2012) FAR - About. Available from:

http://www.randomdance.org/productions/curre nt_productions/far (12 June 2012)

Rinehart, R. (2011) Artworks as Variability Machines. In: Preservation Of Complex Objects Symposia (POCOS), Glasgow, Scotland, 11 Oct 2011. Available from: http://vimeo.com/31440197 (12 June 2012)

Taylor, A. S. (2012) Socio-digital-Systems Alex Taylor. People. Microsoft Research, 2012. Available from:

http://research.microsoft.com/enus/um/people/ast/ (30 May 2012)

transmediale festival. (2006) Festival 2006:

Exhibition. Available from: http://archive.transmediale.de/page/exhibition/e xhibition.0.1.3.html (6 Dec 2011)

Valla, C. (2011) Postcards from Google Earth. IdN: Glitch Issue, 18 no3 2011. 24. 